・森林动态监测样地专题・

\title{
长白山阔叶红松林草本层物种多度 分布格局及其季节动态
}

\author{
张 姗 ${ }^{1,2}$ 萄 菲 ${ }^{1}$ 原作强 ${ }^{1}$ 匡 旭 ${ }^{1,2}$ 贾仕宏 1,2 王芸芸 ${ }^{1,2}$ 索炎炎 ${ }^{1,2}$

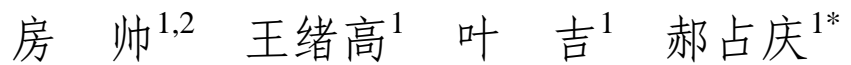

1 (中国科学院沈阳应用生态研究所森林与土壤生态国家重点实验室, 沈阳 110016)

2 (中国科学院大学, 北京 100049)

摘要: 草本层是森林生态系统的重要组成部分, 对维持森林生物多样性具有重要意义。本文以长白山阔叶红松 (Pinus koraiensis)林25 ha固定监测样地为研究平台, 运用不同的统计模型(对数正态模型和对数级数模型)及机理 模型(包括生态位模型: 断棍模型和生态位优先占领模型; 中性模型：复合群落零和多项式模型和Volkov模型), 对 不同季节草本物种多度分布进行拟合。采用Kolmogorov-Smirnov和AIC检验确定最优模型, 以揭示草本层物种多 度分布格局随季节的变化规律, 探讨草本层物种组成与结构背后的生态学过程。结果表明: (1)草本层物种多度分 布季节差异明显。春季各多度级物种数差异不大, 夏季中间种较多, 秋季则是稀有种较多; (2)模型拟合结果显示, 不同季节草本层物种多度分布的最优拟合模型相近。统计模型中对数级数模型表现最优, 机理模型中中性模型的 拟合效果优于生态位模型。复合群落零和多项式模型较好地拟合了春夏季草本物种多度分布, Volkov模型较好地 拟合了秋季草本物种多度分布。综上所述, 尽管长白山阔叶红松林草本植物不同季节的物种多度分布格局不尽一 致, 但其背后的构建机制相似, 中性随机过程在草本层物种多样性维持过程中显得更为重要。

关键词: 森林草本层, 生态位过程, 中性过程, 统计模型, 模型拟合

\section{Herb layer species abundance distribution patterns in different seasons in an old-growth temperate forest in Changbai Mountain, China}

Shan Zhang ${ }^{1,2}$, Fei Lin ${ }^{1}$, Zuoqiang Yuan $^{1}$, Xu Kuang ${ }^{1,2}$, Shihong Jia ${ }^{1,2}$, Yunyun Wang ${ }^{1,2}$, Yanyan Suo ${ }^{1,2}$, Shuai Fang $^{1,2}$, Xugao Wang ${ }^{1}$, $\mathrm{Ji} \mathrm{Ye}^{1}$, Zhanqing Hao ${ }^{1 *}$

1 State Key Laboratory of Forest and Soil Ecology, Institute of Applied Ecology, Chinese Academy of Sciences, Shenyang 110016

2 University of Chinese Academy of Sciences, Beijing 100049

\begin{abstract}
The herbaceous layer is an important component of forest ecosystems and plays an important role in maintaining forest biodiversity. To understand the mechanisms shaping the forest herb community patterns over multiple growing seasons, we used herbaceous data collected in a 25 ha broad-leaved Korean pine (Pinus koraiensis) mixed forest plot in Changbai Mountain, Northeast China and fitted species abundance distributions (SADs) using different models. We used both pure statistical models including log-normal, log-series, and mechanistic models, including two niche models (broken-stick and niche preemption) and two neutral models (metacommunity zero-sum multinomial distribution and Volkov model). Further, we applied the AIC and Kolmogorov-Smirnov tests to compare the goodness-of-fit of these models. Our results showed: (1) The observed SADs of the herb layer varied by season. While there were similar proportions of rare and common species in spring, there were more species with moderate abundances in summer and more rare species in autumn. (2) The best-fitting models of SADs were similar in different seasons. In our analyses, the log-series model was the best pure statistical model across the three seasons. For the mechanistic models, neutral models
\end{abstract}

收稿日期: 2015-04-11; 接受日期: 2015-05-28

基金项目：国家科技基础性工作专项(2012FY112000)和国家自然科学基金(41301057, 31370444)

* 通讯作者 Author for correspondence. E-mail: hzq@iae.ac.cn 
performed better at explaining patterns of SADs than niche models. The metacommunity zero-sum multinomial distribution model was the best model in spring and summer and the Volkov model was the best one in autumn. This indicates that stochastic processes may play a dominant role in maintaining the herb species abundance distributions. Our study showed that although the SAD patterns varied over growing seasons for the herb layer in the broad-leaved Korean pine mixed forest, the underlying mechanisms governing these patterns are similar and neutral models always perform better than niche models in fitting the SADs.

Key words: forest herb layer, niche process, neutral process, statistical model, model fitting

草本层是森林生态系统的重要组成部分。热带 森林中草本植物的丰富度一般可占整个森林维管 植物的14-40\% (Costa, 2004), 而温带森林中超过 $80 \%$ 的维管植物是草本植物 (Whigham, 2004; Gilliam, 2007), 可见草本层植物对维持森林生态系 统物种多样性具有重要意义。

物种多度分布是对群落物种多样性的基本描 述之一, 它反映了物种在一定时空尺度上的分布及 多度格局, 可用于探讨群落构建背后可能存在的生 态学过程, 从而进一步理解生态系统物种多样性的 形成及维持机制(Borda-de-Água et al., 2012)。物种 多度格局的研究始于 20 世纪 30 年代, Motomura (1932)首先提出几何级数模型拟合物种多度分布曲 线, 此后各种新的模型相继出现。常用的模型大致 可分为纯统计模型和机理模型。纯统计模型对物种 多度分布提供经验拟合, 但生物学和生态学意义不 明确, 如常用的对数级数模型 (log-series model) (Fisher et al., 1943) 与对数正态模型 (log-normal model) (Preston, 1948)等。而机理模型重视模型的生 物学意义, 不同的模型反映不同的生态学过程。机 理模型又可进一步分为中性模型和生态位模型, 其 中中性模型强调随机过程的重要性, 为在个体水平 上探讨群落组成搭建了理论框架, 如零和多项式模 型(zero-sum multinomial distribution model, ZSM model)(Hubbell, 2001)等; 生态位模型则把物种多 度与生态位理论密切联系起来, 如断棍模型 (broken-stick model) (MacArthur, 1957, 1960)等。

很多关于物种多度分布的研究均致力于发展 不同的理论模型, 利用这些模型去拟合实际观测数 据, 再根据拟合效果进一步推测物种多样性的形成 机制(McGill et al., 2007; White et al., 2012)。近几十 年来, 物种多度分布模型在各类生态群落中得到广 泛应用, 包括植物群落和昆虫、鱼类及微生物等非 植物群落(Böhning-Gaese \& Bauer, 1996; Hill \& Hamer, 1998; Magurran \& Henderson, 2003; Gans et al., 2005)。国内关于物种多度模型拟合的研究大多 集中于森林群落中的木本植物(冯云等, 2007; 程佳 佳等, 2011; 间琰等, 2012), 这些研究对于理解群落 多样性维持机制, 以及从时空尺度、资源有效性和 干扰的角度, 解释物种组成改变对生态系统功能的 影响具有重要意义(McGill et al., 2007), 但是有关 森林草本层物种多度分布格局与维持机理的研究 还较少。

温带森林草本层的一个显著特征是其物种组 成的季节差异明显, 但目前许多相关研究往往仅以 某个季节的草本层为对象, 忽视了季节动态 (Roberts, 2004; Yu \& Sun, 2013)。一般来说, 在一个 生长季中, 林下草本植物由最初的喜光早春短命植 物逐渐过渡到耐阴的早夏和晚夏植物(Crozier \& Boerner, 1984; Yorks \& Dabydeen, 1999)。阔叶红松 (Pinus koraiensis) 林是长白山区地带性森林植被, 与北温带同纬度其他地区的森林相比, 其建群种更 加独特、物种多样性更为丰富(郝占庆等, 2002)。在 长白山阔叶红松林内, 不同季节草本层优势种与物 种丰富度差异明显, 夏季草本物种数最多, 物种多 度从早春到秋季逐渐减少(郝占庆等, 1994; 李步杭 等, 2008; 夏富才等, 2012)。目前针对长白山阔叶红 松林物种多度的研究大多集中于木本植物(Wang et al., 2008a, b; Yuan et al., 2011)。关于长白山阔叶红 松林内草本植物组成季节动态及分布格局背后的 生态学过程, 目前仍无研究。

本文以长白山阔叶红松林 25 ha样地内不同季 节草本植物为研究对象, 选取 2 个纯统计模型(对数 正态模型和对数级数模型)、2个中性模型(复合群落 零和多项式模型 (metacommunity zero-sum multinomial distribution model, MZSM model)和Volkov模 型(Volkov model))以及 2 个生态位模型(断棍模型和 生态位优先占领模型(niche preemption model)), 对 草本层物种多度曲线进行拟合，试图阐述阔叶红松 林草本层物种多度格局随季节变化的规律, 探讨草 
本层物种分布格局形成的生态学过程, 以期更充分 地理解阔叶红松林群落结构与多样性格局。

\section{1 研究地区概况}

研究地位于长白山北坡的长白山自然保护区 内, 地理位置为 $42^{\circ} 12^{\prime} \mathrm{N} 、 128^{\circ} 32^{\prime} \mathrm{E}$, 气候为受季风 影响的温带大陆性气候, 冬季漫长而寒冷, 夏季温 暖多雨且短暂。年平均气温 $3.6^{\circ} \mathrm{C}$, 年平均降水量 $700 \mathrm{~mm}$, 且多集中在夏季(张弥等, 2005)。土壤为山 地暗棕色森林土(徐广山等, 1980)。

\section{2 方法}

\section{1 样地建立与调查}

2004年夏, 我们参照BCI 50 ha样地的技术规 范, 在长白山自然保护区阔叶红松林内建立了1块 $500 \mathrm{~m} \times 500 \mathrm{~m}$ 的固定样地, 并对样地内胸径 $(\mathrm{DBH})$ $\geq 1 \mathrm{~cm}$ 的所有木本植物的种类、胸径、坐标位置进 行调查记录, 此后每5年复查 1 次。样地平均海拔为 $801.5 \mathrm{~m}$, 最高海拔 $809.5 \mathrm{~m}$, 最低海拔791.8 m。整个 样地较为平缓, 但局部地区有一些小的起伏(Hao et al., 2007)。

\section{2 草本样方设置与调查}

2005年在 25 ha固定样地内设置了 150 个相对均 匀分布的种子收集器(张健等, 2008)。2014年在每个 种子收集器的西面与北面 $2 \mathrm{~m}$ 处各设置 1 个 $1 \mathrm{~m} \times 1$ $\mathrm{m}$ 的样方, 调查样方内所有草本物种种类和多度。 具体调查时间为：4月24-27日(春季), 6月26-29日 (夏季), 8月31日-9月 2 日(秋季), 共计调查了 148 个 种子收集器(其中 2 个受倒木干扰并未设置草本调查 样方)所对应的 296 个小样方。

\section{3 模型拟合}

对记录到的不同季节草本层物种多度数据分 别构建对数正态模型、对数级数模型、断棍模型、 生态位优先占领模型、集合群落零和多项式模型和 Volkov模型，拟合物种多度分布曲线。各模型简介 如下:

(1) 对数正态模型。由Preston (1948)提出, 该模 型认为群落中总个体数 $(N)$ 的对数符合正态分布, 则第 $i$ 个物种的多度为:

$$
N_{\mathrm{i}}=e^{[\log (\mu)+\log (\sigma) \Phi]}
$$

式中, $\mu$ 和 $\sigma$ 分别表示正态分布的均值和方差, $\Phi$ 表示 正态偏差。
(2) 对数级数模型。由Fisher等(1943)提出, 该 模型是一个离散分布模型, 它适合描述不含 0 的正 整数, 即没有个体存在的种不予考虑。则群落中多 度为 $n$ 的物种数量 $S$ 为:

$$
S(n)=\alpha \frac{X^{n}}{n}
$$

模型中 $\alpha$ 代表群落的多样性指数; $0<\mathrm{X} \leq 1, \mathrm{X}$ 是常数, 与群落大小有关。

(3) 断棍模型。由MacArthur $(1957,1960)$ 提出, 该模型假定一个群落中的总生态位(资源总量)是等 于 1 的一条棍, 在棍上随机设 $N-1$ 个点, 把棍分割 为 $N$ 段, 代表生态位被 $N$ 个物种所占有。该模型假定 $N$ 个物种分类地位接近，竞争能力也相似，而且同 时在群落中出现, 群落中物种的总个体数为 $J$, 则 该模型中第 $i$ 个物种的多度为:

$$
N_{\mathrm{i}}=\frac{J}{N} \sum_{x=i}^{n} \frac{1}{x}
$$

(4) 生态位优先占领模型(Whittaker, 1965)。该 模型认为在群落中最优势的物种先占用总生态位 的 $k$ 份，次优势种再占用剩余的 $k$ 份，即 $k(1-k)$, 以 此类推, 直到剩下的资源不能再维持一个物种的生 存为止。该模型保证优势种优先利用资源, 所有种 在生态位占有上明显形成一个等级。以 $N_{1}$ 表示模型 中最优势种的物种多度, 则该模型中第 $i$ 个物种的 多度为:

$$
N_{\mathrm{i}}=N_{1}(1-k)^{i-1}
$$

(5) 复合群落零和多项式模型 (Hubbell, 2001; Alonso \& McKane, 2004)。该模型认为任意取样点 (random sample)的物种多度分布是中性复合群落在 随机生态漂变作用下的产物, 模型包括两个参数: 取样点物种的个体数 $(J)$ 和基本多样性指数(fundamental biodiversity number, $\theta$ )。在一个群落中, 任意 一个个体死亡后，它被 1 个新物种取代的概率是 $v$, 而被任意一个余下个体的后代取代的概率是 $1-v$, 则 $\theta=2 J v$ 。由于取样点的物种个体数 $J$ 是确定的, 因 此该模型只包含一个不确定参数 $\theta$ 。该模型认为复 合群落中, 任意取样点内多度为 $n$ 的物种数量 $S$ 为:

$$
\begin{gathered}
\left.S(n)=\frac{\theta}{n} \int_{0}^{J} f_{n, 1}(y)\left(1-\frac{n}{J}\right)\right)^{\theta-1} d y \\
f_{n, \delta}(y)=\frac{1}{\Gamma(n) \delta^{n}} \exp \left(-\frac{y}{\delta}\right) y^{n-1} \\
\Gamma(z)=\int_{0}^{\infty} t^{z-1} e^{-t} d t
\end{gathered}
$$


(6) Volkov模型(Volkov et al., 2003)。该模型在 复合群落零和多项式模型的基础上增加了参数迁 移系数 $m$, 并假设物种从复合群落到局域群落的迁 移系数 $m$ 是固定不变的。模型中局域群落中多度为 $n$ 的物种数量 $S$ 为:

$$
\begin{gathered}
S(n)=\theta \frac{J !}{n !(J-n) !} \frac{\Gamma(\gamma)}{\Gamma(J+\gamma)} \int_{0}^{\gamma} \frac{\Gamma(n+y)}{\Gamma(1+y)} \frac{\Gamma(J-n+\gamma-y)}{\Gamma(\gamma-y)} \exp \left(-\frac{y \theta}{\gamma}\right) d y \\
\Gamma(z)=\int_{0}^{\infty} t^{z-1} e^{-t} d t \\
\gamma=\frac{m(J-1)}{1-m}
\end{gathered}
$$

式中, $\gamma$ 为迁移到局域群落的个体数。

\section{4 模型拟合效果检验}

采用Kolmogorov-Smirnov检验模型拟合结果与 实际观测分布的差异, 若 $P<0.01$, 则表示该模型被 拒绝。

\subsection{AIC准则}

AIC准则(Akaike information criterion, AIC)是 评估统计模型拟合优良性的一个标准, 在模型选择 时, 含有的参数越少、概率密度分布与真实数据越 接近, 则AIC值越小, 模型被认为是最优模型。

\section{6 数据处理}

将物种的多度以 2 为底进行对数转换, 并合并 相邻多度区间进行分组。

文中所有的统计分析与模型拟合均采用 R-3.1.2(R Development Core Team, 2014)中的软件 包“sads”完成。

\section{3 结果}

\section{1 草本植物多度分布}

长白山阔叶红松林草本植物不同季节的物种 多度分布结果表明, 春季常见种与稀有种的种数差
异并不显著。夏季中间种较多, 秋季稀有种较多 (图1)。

\section{2 草本植物多度分布曲线拟合}

采用 6 个模型对 3 个季节草本层物种多度进行 拟合, 结果显示: K-S检验接受了 2 个纯统计模型和 2 个中性模型，拒绝了 2 个生态位模型。从K-S检验接 受的模型中, 选取 AIC 值小的模型为较优模型, 则 在纯统计模型中, 对数级数模型是 3 个季节草本植 物多度分布的最优拟合模型。而在中性模型中，复 合群落零和多项式模型是春季和夏季的最优拟合 模型; Volkov模型为秋季的最优拟合模型(表1)。

阔叶红松林草本层物种多度分布模型拟合效果 如图2所示。在纯统计模型中, 对数正态模型和对数 级数模型与不同季节的草本物种多度分布曲线大 致吻合, 而对数级数模型对于稀有种的拟合要优于 对数正态模型。在中性模型中, 复合群落零和多项 式模型和Volkov模型都能很好地拟合春季和秋季实 际草本物种多度分布; 夏季, 复合群落零和多项式 模型对草本物种多度的拟合良好, Volkov模型对低 多度级物种的拟合较好, 对中多度级和高多度级物 种的拟合与实际情况相差较大(中性模型参数见表 2)。生态位模型对不同季节草本层物种多度分布的 拟合效果都较差。

\section{4 讨论}

与郝占庆等(1994)的结果一致, 我们的研究也 表明长白山阔叶红松林草本层物种多度分布季节 差异明显, 产生这一现象的原因可能是由于不同季 节林下草本层物种组成不同。在温带森林中, 由于 植物的物候特征，草本植物在一年中的变化很大： 早春短命植物在乔灌木展叶之前完成其年生活史;

\begin{tabular}{|c|c|c|c|c|c|c|c|c|c|c|c|c|}
\hline \multirow[t]{2}{*}{$\begin{array}{l}\text { 季节 } \\
\text { Season }\end{array}$} & \multicolumn{2}{|c|}{$\begin{array}{l}\text { 对数正态模型 } \\
\text { Log-normal } \\
\text { model }\end{array}$} & \multicolumn{2}{|c|}{$\begin{array}{c}\text { 对数级数模型 } \\
\text { Log-series model }\end{array}$} & \multicolumn{2}{|c|}{$\begin{array}{c}\text { 断棍模型 } \\
\text { Broken-stick model }\end{array}$} & \multicolumn{2}{|c|}{$\begin{array}{c}\text { 生态位优先占领模型 } \\
\text { Niche preemption } \\
\text { model }\end{array}$} & \multicolumn{2}{|c|}{$\begin{array}{c}\text { 复合群落零和多项式模型 } \\
\text { Metacommunity zero-sum multi- } \\
\text { nomial distribution model }\end{array}$} & \multicolumn{2}{|c|}{$\begin{array}{l}\text { Volkov模型 } \\
\text { Volkov model }\end{array}$} \\
\hline & AIC值 & $\mathrm{D}$ & AIC值 & $\mathrm{D}$ & AIC值 & $\mathrm{D}$ & AIC值 & $\mathrm{D}$ & AIC值 & $\mathrm{D}$ & AIC值 & $\mathrm{D}$ \\
\hline $\begin{array}{l}\text { 春季 } \\
\text { Spring }\end{array}$ & 901.3 & 0.11 & 885.3 & 0.08 & $1,102.9$ & $0.51 * *$ & $307,698.7$ & $0.31 * *$ & 885.5 & 0.08 & 888.9 & 0.11 \\
\hline $\begin{array}{l}\text { 夏季 } \\
\text { Summer }\end{array}$ & 883.2 & 0.08 & 876.8 & 0.08 & $1,038.3$ & $0.46^{* *}$ & $112,380.8$ & $0.34 * *$ & 877.3 & 0.08 & 938.0 & 0.20 \\
\hline 秋季 & 801.2 & 0.10 & 789.5 & 0.10 & 981.6 & $0.57 * *$ & $63,593.5$ & $0.44 * *$ & 790.1 & 0.11 & 789.9 & 0.12 \\
\hline
\end{tabular}

表1 不同季节6种模型的拟合优度检验

Table 1 Goodness-of-fit test of six models in different seasons

Autumn

AIC，赤池信息准则; D, K-S检验统计值。 $* * P<0.01$

AIC, Akaike information criterion; D, Statistic of K-S test. 

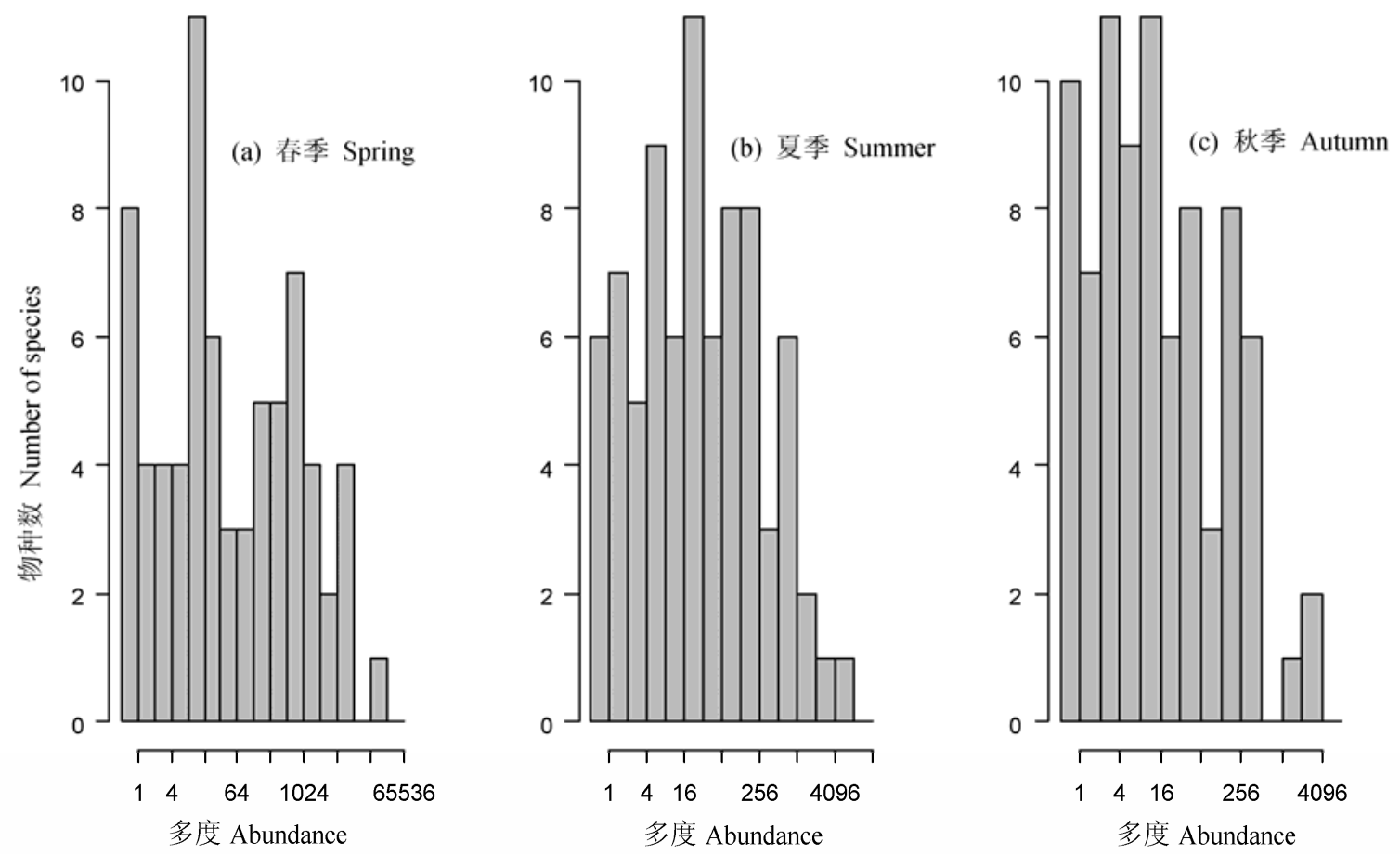

图1 长白山阔叶红松林草本植物不同季节物种多度直方图

Fig. 1 Species abundance histograms in different seasons in the broad-leaved Korean pine mixed forest in Changbai Mountain

表2 长白山阔叶红松林不同季节中性模型参数

Table 2 Parameters of neutral model in different seasons in the broad-leaved Korean pine mixed forest in Changbai Mountain

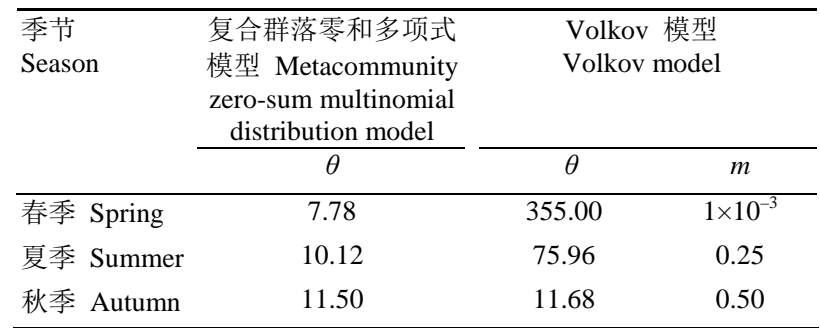

$\theta$ 指基本多样性指数, $m$ 指迁移系数。

$\theta$ represents fundamental biodiversity number and $m$ represents immigration rate.

早夏植物在乔灌木展叶前开始生长, 秋季调零; 晚 夏植物在乔灌层展叶之后开始萌芽, 在秋季结束生 活史(Moore \& Vankat, 1986; Murphy \& McCarthy, 2014)。虽然不同季节的草本层物种多度分布有差 异, 但模型的拟合结果相似, 表明不同季节的草本 层可能具有相似的维持机制。在美国东北部温带森 林关于草本植物多样性与季节动态的研究也得出 了类似的结论: 在物种组成不同的前提下, 林下草 本层物种多样性的季节差异并不显著; 占用同一资
源的草本物种数以及草本群落的主要结构并不随 着季节的变化而变化; 春季与夏季草本优势种在空 间上的显著相关性表明不同季节草本优势种可能 有着相同的分布喜好(Bratton, 1976; McEwan \& Muller, 2011)。导致不同季节草本层多样性维持机 制相似的原因目前还不清楚, McEwan和 Muller (2011)提出一种假设: 温带森林经过漫长的演替, 群落中草本植物数量接近群落的最大容纳量, 尽管 不同季节草本物种组成不同, 但维持群落最大物种 承载量的机制可能是类似的, 目前该假设的正确性 并没有得到验证。

中性模型能够很好地拟合长白山阔叶红松林 各个季节草本层物种多度分布, 表明随机过程可能 在草本群落的构建过程中发挥重要作用。阔叶红松 林是该区域群落演替的顶极阶段, 群落结构复杂, 物种组成和数量比例相对稳定, 种间作用并不强 烈。因此, 在草本层物种多度分布格局的形成过程 中, 物种间生态位分化的作用可能并不大, 代表中 性过程的随机扩散对群落构建的作用更大。已有的 研究也表明扩散和定植是温带森林草本群落构建 的重要影响因子, 草本植物的分布可以看作是斑块 
(a) 春季 Spring

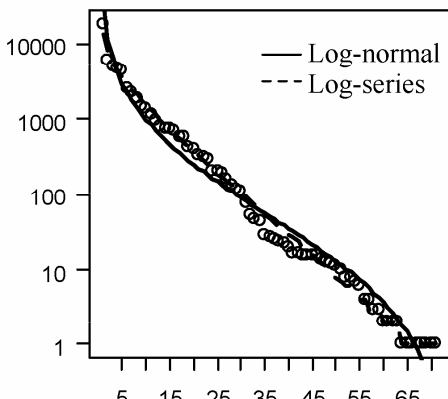

$\begin{array}{lllllll}5 & 15 & 25 & 35 & 45 & 55 & 65\end{array}$
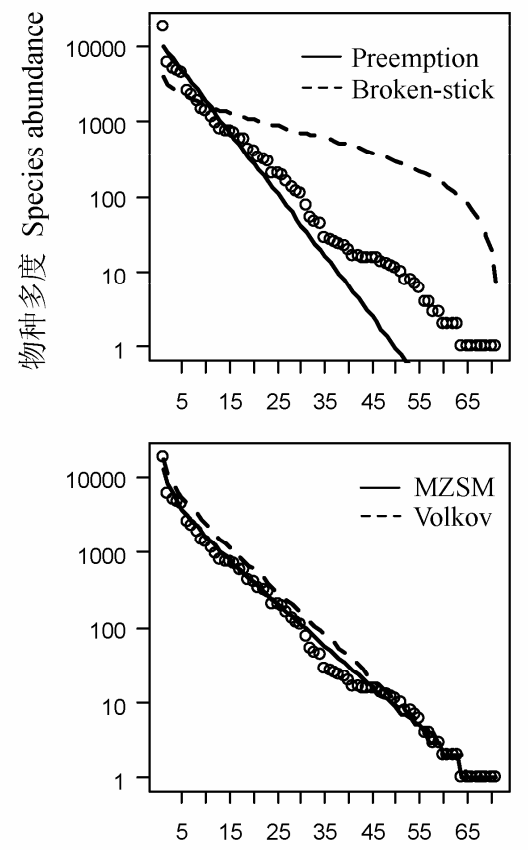

(b) 夏季 Summer

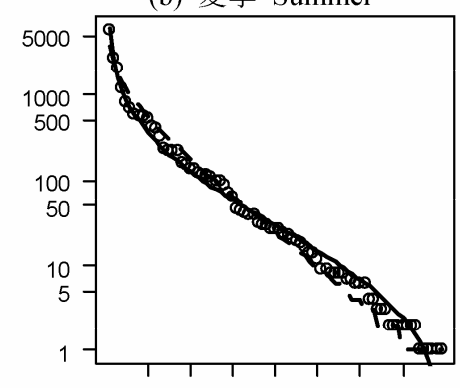

$\begin{array}{lllllll}10 & 20 & 30 & 40 & 50 & 60 & 70\end{array}$

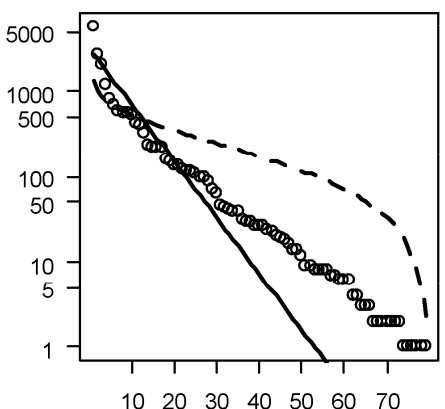

$\begin{array}{lllllll}10 & 20 & 30 & 40 & 50 & 60 & 70\end{array}$

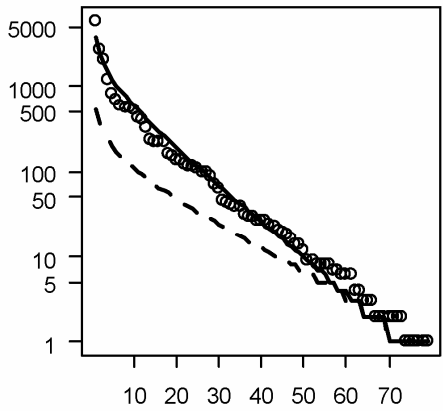

(c) 秋季 Autumn

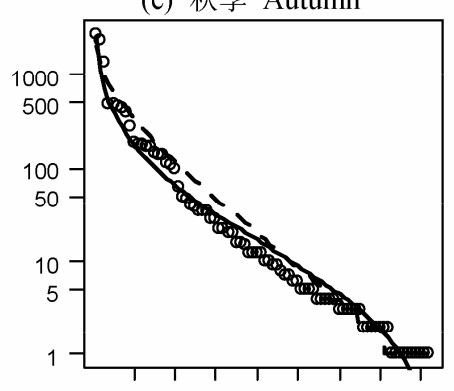

1020304050607080

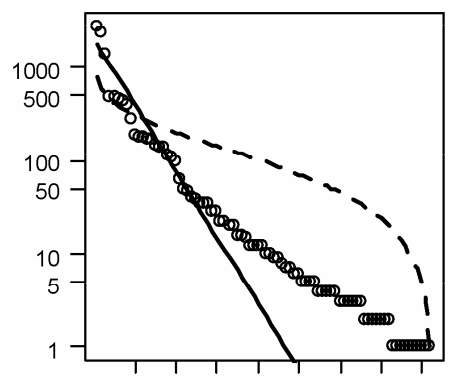

$\begin{array}{llllllll}10 & 20 & 30 & 40 & 50 & 60 & 70 & 80\end{array}$

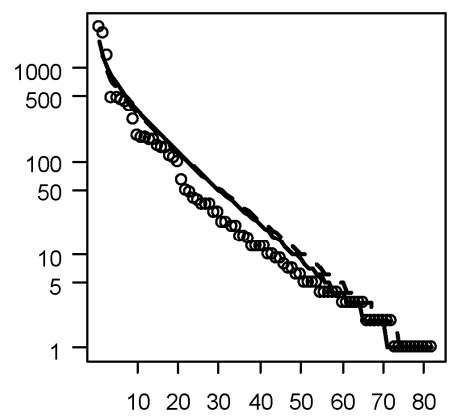

物种优势度 Species rank in abundance

图2 不同季节长白山阔叶红松林草本的物种多度分布及模型拟合。观测值以点表示, 图中Log-normal指对数正态模型, Log-series指对数级数模型, Preemption指生态位优先占领模型, Broken-stick指断棍模型, MZSM指复合群落零和多项式模 型, Volkov指Volkov模型。

Fig. 2 Herb species abundance distributions and model fittings in different seasons in the broad-leaved Korean pine mixed forest in Changbai Mountain. Observed values are shown by points, Log-normal, Log-series, Preemption, Broken-stick, MZSM and Volkov represent log-normal model, log-series model, niche preemption model, broken-stick model, metacommunity zero-sum multinomial distribution model and Volkov model, respectively.

生境内以及斑块生境间物种传播的结果(Ehrlén \& Eriksson, 2000; Svenning et al., 2008)。

很多研究认为生态位理论和中性理论并不是 相互排斥的, 它们在群落构建中共同起作用(Chave et al., 2002; Harpole \& Tilman, 2006; Legendre et al., 2009; Dumbrell et al., 2010), 但是本研究并未发现 生态位模型能够很好地拟合长白山阔叶红松林林 下草本层物种多度格局的证据。这可能与长白山样 地本身的特点有关, 我们的样地地形平坦, 25 ha样
地最大高差不足 $18 \mathrm{~m}$, 而地形是环境异质性的重要 评价标准, 地形平坦的样地环境异质性相对较低 (Brown et al., 2013)。此前对样地内木本植物的研究 也表明扩散限制比环境异质性能解释木本植物多 样性格局更多的变异(Zhang et al., 2009; Yuan et al., 2011; Wang et al., 2011)。而在地形复杂、环境异质 性较大的古田山亚热带常绿阔叶林24 ha样地开展 的类似研究表明, 仅地形因子就可以解释样地内木 本植物多样性 30\%的变异, 与中性过程贡献相当 
(Legendre et al., 2009)。由此推断, 和木本植物类似, 地形平坦的长白山样地本身环境较为均质, 缺乏有 效的生境过滤因子, 草本植物物种多度分布格局可 能受确定性的生态位过程影响不大。

虽然物种多度分布是描述群落组成的基本方 法, 也是理解群落结构的基石, 但由于通过格局来 推断其形成机制具有一定的局限性，如不同的机制 可能会产生相同的格局, 所以仅依据物种多度分布 曲线的模型拟合结果就确定群落维持机制的方法 并不完善。物种多度分布是解释群落构建机制的 “必要非充分”条件(McGill et al., 2007), 模型与实 际数据的拟合效果良好也并不能完全验证理论 (Magurran, 2005; Volkov et al., 2005)。因此, 本文的 分析只能初步得出中性随机过程在长白山阔叶红 松林草本层的构建中起主导作用, 若想进一步明确 中性随机过程和确定性过程在群落形成过程中的 相对贡献, 需要研究地形、土壤等环境因子和周边 木本植物等生物因子以及空间因子对草本植物组 成与结构的影响。

\section{参考文献}

Alonso D, McKane AJ (2004) Sampling Hubbell's neutral theory of biodiversity. Ecology Letters, 7, 901-910.

Böhning-Gaese K, Bauer HG (1996) Changes in species abundance, distribution, and diversity in a central European bird community. Conservation Biology, 10, 175-187.

Borda-de-Água L, Borges PA, Hubbell SP, Pereira HM (2012) Spatial scaling of species abundance distributions. Ecography, 35, 549-556.

Bratton SP (1976) Resource division in an understory herb community: responses to temporal and microtopographic gradients. American Naturalist, 110, 679-693.

Brown C, Burslem DFRP, IIIiana JB, Bao L, Brockelman W, Cao M, Chang LW, Dattaraja HS, Davies S, Gunatilleke CVS (2013) Multispecies coexistence of trees in tropical forests: spatial signals of topographic niche differentiation increase with environmental heterogeneity. Proceedings of the Royal Society B: Biological Sciences, 280, 1-8.

Chave J, Muller-Landau HC, Levin SA (2002) Comparing classical community models: theoretical consequences for patterns of diversity. American Naturalist, 159, 1-23.

Cheng JJ (程佳佳), Mi XC (米湘成), Ma KP (马克平), Zhang JT (张金屯) (2011) Responses of species-abundance distribution to varying sampling scales in a subtropical broad-leaved forest. Biodiversity Science (生物多样性), 19, 168-177. (in Chinese with English abstract)

Costa FRC (2004) Structure and composition of the ground-herb community in a terra-firme Central Amazonian forest. Acta Amazonica, 34, 53-59.
Crozier C, Boerner RJ (1984) Correlations of understory herb distribution patterns with microhabitats under different tree species in a mixed mesophytic forest. Oecologia, 62, 337-343.

Dumbrell AJ, Nelson M, Helgason T, Dytham C, Fitter AH (2010) Relative roles of niche and neutral processes in structuring a soil microbial community. The ISME Journal, 4, 337-345.

Ehrlén J, Eriksson O (2000) Dispersal limitation and patch occupancy in forest herbs. Ecology, 81, 1667-1674.

Feng Y (冯云), Ma KM (马克明), Zhang YX (张育新), Qi J (祁建), Zhang JY (张洁瑜) (2007) Species abundance distribution of Quercus liaotungensis forest along altitudinal gradient in Dongling Mountain, Beijing. Acta Ecologica Sinica (生态学报), 27, 4743-4750. (in Chinese with English abstract)

Fisher RA, Corbet AS, Williams CB (1943) The relation between the number of species and the number of individuals in a random sample of an animal population. Journal of Animal Ecology, 12, 42-58.

Gans J, Wolinsky M, Dunbar J (2005) Computational improvements reveal great bacterial diversity and high metal toxicity in soil. Science, 309, 1387-1390.

Gilliam FS (2007) The ecological significance of the herbaceous layer in temperate forest ecosystems. BioScience, 57, 845-858.

Hao ZQ (郝占庆), Zhao SD (赵士洞), Tao DL (陶大立) (1994) Species diversity and its seasonal dynamics of herbs in a broad-leaved Korean pine forest on northern slope of the Changbai Mountain. Chinese Biodiversity (生物多样 性), 2, 125-132. (in Chinese with English abstract)

Hao ZQ (郝占庆), Guo SL (郭水良), Cao T (曹同) (2002) Plant Diversity and Distribution Patterns in Changbai Mountain (长白山植物多样性及其格局). Liaoning Science and Technology Publishing House, Shenyang. (in Chinese)

Hao ZQ, Zhang J, Song B, Ye J, Li BH (2007) Vertical structure and spatial associations of dominant tree species in an old-growth temperate forest. Forest Ecology and Management, 252, 1-11.

Harpole WS, Tilman D (2006) Non-neutral patterns of species abundance in grassland communities. Ecology Letters, 9, 15-23.

Hill JK, Hamer KC (1998) Using species abundance models as indicators of habitat disturbance in tropical forests. Journal of Applied Ecology, 35, 458-460.

Hubbell SP (2001) The Unified Neutral Theory of Biodiversity and Biogeography. Princeton University Press, Princeton.

Legendre P, Mi XC, Ren HB, Ma KP, Yu MJ, Sun IF, He FL (2009) Partitioning beta diversity in a subtropical broad-leaved forest of China. Ecology, 90, 663-674.

Li BH (李步杭), Zhang J (张健), Yao XL (姚晓琳), Ye J (叶 吉), Wang XG (王绪高), Hao ZQ (郝占庆) (2008) Seasonal dynamics and spatial distribution patterns of herbs diversity in broadleaved Korean pine (Pinus koraiensis) mixed forest in Changbai Mountains. Chinese Journal of Applied Ecology (应 
用生态学报), 19, 467-473. (in Chinese with English abstract) MacArthur RH (1957) On the relative abundance of bird species. Proceedings of the National Academy of Sciences, USA, 43, 293-295.

MacArthur RH (1960) On the relative abundance of species. American Naturalist, 94, 25-36.

Magurran AE (2005) Species abundance distributions: pattern or process? Functional Ecology, 19, 177-181.

Magurran AE, Henderson PA (2003) Explaining the excess of rare species in natural species abundance distributions. $\mathrm{Na}$ ture, 422, 714-716.

McEwan RW, Muller RN (2011) Dynamics, diversity, and resource gradient relationships in the herbaceous layer of an old-growth Appalachian forest. Plant Ecology, 212, 11791191.

McGill BJ, Etienne RS, Gray JS, Alonso D, Anderson MJ, Benecha HK, Dornelas M, Enquist BJ, Green JL, He F (2007) Species abundance distributions: moving beyond single prediction theories to integration within an ecological framework. Ecology Letters, 10, 995-1015.

Moore MR, Vankat JL (1986) Responses of the herb layer to the gap dynamics of a mature beech-maple forest. American Midland Naturalist, 115, 336-347.

Motomura I (1932) On the statistical treatment of communities. Japanese Journal of Zoology, 44, 379-383.

Murphy SJ, McCarthy BC (2014) Temporal change in the herbaceous understory community of an old-growth forest: from seasons to decades. Plant Ecology, 215, 221-232.

Preston FW (1948) The commonness, and rarity, of species. Ecology, 29, 254-283.

R Development Core Team (2014) R: A Language and Environment for Statistical Computing. R Foundation for Statistical Computing, Vienna, Austria. http://www.R-project.org/. (accessed 2014-08-16)

Roberts MR (2004) Response of the herbaceous layer to natural disturbance in North American forests. Canadian Journal of Botany, 82, 1273-1283.

Svenning JC, Normand S, Skov F (2008) Postglacial dispersal limitation of widespread forest plant species in nemoral Europe. Ecography, 31, 316-326.

Volkov I, Banavar JR, He F, Hubbell SP, Maritan A (2005) Density dependence explains tree species abundance and diversity in tropical forests. Nature, 438, 658-661.

Volkov I, Banavar JR, Hubbell SP, Maritan A (2003) Neutral theory and relative species abundance in ecology. Nature, 424, 1035-1037.

Wang XG, Hao ZQ, Ye J, Zhang J, Li BH, Yao XL (2008a) Spatial pattern of diversity in an old-growth temperate forest in northeastern China. Acta Oecologica, 33, 345-354.

Wang XG, Hao ZQ, Ye J, Zhang J, Li BH, Yao XL (2008b) Spatial variation of species diversity across scales in an old-growth temperate forest of China. Ecological Research, 23, 709-717.

Wang XG, Wiegand T, Wolf A, Howe R, Davies SJ, Hao ZQ (2011) Spatial patterns of tree species richness in two temperate forests. Journal of Ecology, 99, 1382-1393.
Whigham DF (2004) Ecology of woodland herbs in temperate deciduous forests. Annual Review of Ecology, Evolution, and Systematics, 35, 583-621.

White EP, Thibault KM, Xiao X (2012) Characterizing species abundance distributions across taxa and ecosystems using a simple maximum entropy model. Ecology, 93, 1772-1778.

Whittaker RH (1965) Dominance and diversity in land plant communities. Science, 147, 250-260.

Xia FC (夏富才), Pan CF (潘春芳), Zhao XH (赵秀海), He HY (何海燕), Zhou HC (周海城) (2012) Influence of overstory on seasonal variability of understory herbs in primary broad-leaved Korean pine forest of Changbai Mountain. Acta Botanica Boreali-Occidentalia Sinica (西北植物学报), 32, 370-376. (in Chinese with English abstract)

Xu GS (徐广山), Ding GF (丁桂芳), Zhang YH (张玉华), Cheng BR (程伯容) (1980) A primary study on soil humus and its characteristics in the main forests on northern slope of Changbai Mountain. Forest Ecosystem Research (森林生态 系统研究), 1, 215-220. (in Chinese with English abstract)

Yan Y (间琰), Zhang CY (张春雨), Zhao XH (赵秀海) (2012) Species-abundance distribution patterns at different successional stages of conifer and broad-leaved mixed forest communities in Changbai Mountains, China. Chinese Journal of Plant Ecology (植物生态学报), 36, 923-934. (in Chinese with English abstract)

Yorks TE, Dabydeen S (1999) Seasonal and successional understory vascular plant diversity in second-growth hardwood clearcuts of western maryland, USA. Forest Ecology and Management, 119, 217-230.

Yu M, Sun OJ (2013) Effects of forest patch type and site on herb-layer vegetation in a temperate forest ecosystem. Forest Ecology and Management, 300, 14-20.

Yuan ZQ, Gazol A, Wang X, Lin F, Ye J, Bai XJ, Li BH, Hao ZQ (2011) Scale specific determinants of tree diversity in an old growth temperate forest in China. Basic and Applied Ecology, 12, 488-495.

Zhang J (张健), Hao ZQ (郝占庆), Li BH (李步杭), Ye J (叶 吉), Wang XG (王绪高), Yao XL (姚晓琳) (2008) Composition and seasonal dynamics of seed rain in broad-leaved Korean pine (Pinus koraiensis) mixed forest, Changbai Mountain. Acta Ecologica Sinica (生态学报), 28, 2445-2454. (in Chinese with English abstract)

Zhang J, Hao ZQ, Song B, Li BH, Wang XG, Ye J (2009) Fine-scale species co-occurrence patterns in an old-growth temperate forest. Forest Ecology and Management, 257, 2115-2120.

Zhang M (张弥), Guan DX (关德新), Han SJ (韩士杰), Wu JB (吴家兵), Zhang JH (张军辉), Jin MS (金明淑), Xu H (徐 浩), He X (何秀), Dai GH (戴冠华) (2005) Climatic dynamics of broad-leaved Korean pine forest in Changbai Mountain during the last 22 years. Chinese Jounal of Ecology (生态学杂志), 24, 1007-1012. (in Chinese with English abstract)

(责任编委: 张大勇 责任编辑: 问文杰) 